\title{
Low-fired Y-type hexagonal ferrite for hyper frequency applications
}

\author{
Yang BAI $^{\mathrm{a},{ }^{*}}$, Wenjie ZHANG ${ }^{\mathrm{a}}$, Lijie QIAO ${ }^{\mathrm{a}}$, Ji ZHOU ${ }^{\mathrm{b}}$ \\ ${ }^{a}$ Key Laboratory of Environmental Fracture (Ministry of Education), University of Science and Technology Beijing, \\ Beijing 100083, China \\ ${ }^{b}$ State Key Lab of New Ceramics and Fine Processing, Department of Materials Science and Engineering, \\ Tsinghua University, Beijing 100084, China
}

Received June 3, 2012; Accepted July 12, 2012

(C) The Author(s) 2012. This article is published with open access at Springerlink.com

\begin{abstract}
Y-type hexagonal ferrite with planar magnetocrystalline anisotropy has ultrahigh cut-off frequency up to $\mathrm{GHz}$ and excellent magnetic properties in hyper frequency range, so that is regarded as the most suitable material in correpongding inductive devices and components. The technology of low temperature cofired ceramics for surface-mounted multilayer chip components needs ferrite to be sintered well under $900{ }^{\circ} \mathrm{C}$ to avoid the melting and diffusion of $\mathrm{Ag}$ inner electrode during the cofiring process. To lower the sintering temperature of Y-type hexagonal ferrite, there are several methods, (1) using nano-sized starting powders, (2) substitution by low-melting elements, (3) adding sintering additives, and (4) introducing lattice defect. In this paper, the effects of different methods on the sintering behavior and the magnetic properties were discussed in detail.
\end{abstract}

Key words: hexagonal ferrite; magnetic material; low temperature cofiring ceramics

\section{Introduction}

With the development of modern electronic technology, the fast spread of portable electronic products promotes the trends of electronic technology towards miniaturization, integration and high frequency. The development of computer and wireless technology creates a great demand for novel chip inductive devices in hyper frequency, which need the magnetic material has excellent electromagnetic properties in hyper frequency. The mature spinel ferrites cannot

* Corresponding author.

E-mail: baiy@mater.ustb.edu.cn; Tel: 86-10-62334493;

Fax: 86-10-62332345 serve as the suitable material in hyper frequency because the cubic magnetic structure limits their cut-off frequency below $100 \mathrm{MHz}$ [1]. Soft-magnetic hexagonal ferrites, including Z-type and Y-type hexagonal ferrites, have a cut-off frequency one order of magnitude higher than that of spinel ferrites, so they are the desirable candidate for the inductive components in hyper frequency. Although $\mathrm{Co}_{2} \mathrm{Z}$, the most typical Z-type hexagonal ferrite, has high permeability in hyper frequency, its high sintering temperature beyond $1300{ }^{\circ} \mathrm{C}$ is hard to meet the need of low temperature cofired ceramics (LTCC) technology for surface-mounted multilayer chip components [2-5]. Hence, Y-type hexagonal ferrite becomes the best choice, because it has good magnetic properties in hyper frequency and relatively low 
sintering temperature $\left(\sim 1150{ }^{\circ} \mathrm{C}\right)[6-8]$.

The multilayer chip inductive components have complex structure with spiral inner electrode, which demands excellent cofiring match between electrode and magnetic material. For multilayer chip inductive components, such as multilayer chip inductor (MLCI) and multilayer chip beads (MLCB), Ag is the best choice as inner electrode, due to high electric and thermal conductivity. However, the melting and diffusion of $\mathrm{Ag}$ near the melting point can remarkably destroys the performance of devices $[9,10]$, and its melting point of $961{ }^{\circ} \mathrm{C}$ is much lower than the sintering temperature of most ferrites. There are two solutions, raising the melting point of $\mathrm{Ag}$ or lowering the sintering temperature of ferrites. The melting point of silver alloy can be raised by noble metals, such as $\mathrm{Pd}$, but the remarkable increment of price, about several dozens of times, prevents the application. Hence, it becomes the key in practical production of MLCI to lower the sintering temperature of ferrites to $900{ }^{\circ} \mathrm{C}$.

Sintering is an important process to create dense ceramics from powders [11]. The driving force for densification is the reduction of free energy by the decrease in surface area and the replacement of solid-vapor interfaces (particle surface) by solid-solid interfaces (grain boundary). The sintering process carries out based on mass transfer, either in liquid phase or solid phase, where the former is more efficient than the latter. Hence, both increasing the driving force and improving the mass transfer can promote the sintering process and lower the sintering temperature. The driving force of sintering can be raised effectively by adopting nano-sized starting powders with large surface area. The mass transfer in liquid phase can be promoted by substitution or sintering additives with low melting point. And the mass transfer in solid phase can be promoted by introducing specific defect in lattice, such as vacancy.

In this paper, some effective low firing methods are concluded, (1) nano technology, (2) substitution in lattice, (3) sintering additives and (4) lattice defect, where the effects on the sintering behavior and the magnetic properties were compared and discussed in detail.

\section{Nano technology}

The driving force of sintering can be great raised by using smaller starting particles with larger surface area, so using nano-sized particles, instead of micron-sized, can promote the sintering process and lower the sintering temperature. It also benefit the mass transfer in sintering process, which is affected by the change in pressure and differences in free energy across the curved surface [11]. These effects become larger in magnitude if the size of the particle is smaller, especially in nanoscale. Some researchers have reported the preparation of nano-sized Y-type hexagonal ferrite powders and corresponding electromagnetic properties [12-18]. Here, the powders prepared by citrate sol-gel process are set as example to clarify the effect of highly active nano-sized powders on phase formation, sintering behavior and magnetic properties.

Figure 1 shows the XRD pattern of the powders prepared by citrate sol-gel process and calcined at $900{ }^{\circ} \mathrm{C}$. As indexing by the standard XRD spectrum, the samples calcined at $900{ }^{\circ} \mathrm{C}$ are pure phase of Y-type hexagonal ferrite, where the temperature is about $100{ }^{\circ} \mathrm{C}$ lower than that of the micro-sized samples prepared by solid-state reaction method. The high activity of nano-sized powder promotes the mass transfer and solid state reaction, so the phase formation temperature is lowered obviously.

The large surface energy of nano-sized starting particles endows the sample high sintering activity, so they can be sintered well under low temperature. As shown in Fig. 2, the samples with nano-sized powders can be sintered well at $900{ }^{\circ} \mathrm{C}$, whose density is beyond $95 \%$ of theoretical density. In addition, the shrinkage rate is much larger than that of the sample

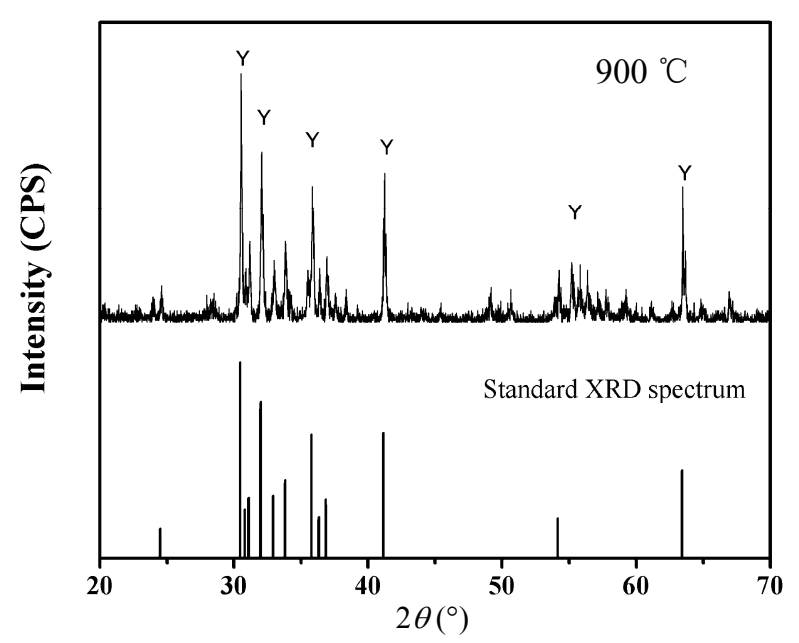

Fig. 1 XRD pattern of $\mathrm{Ba}_{2} \mathrm{Zn}_{0.8} \mathrm{Co}_{0.8} \mathrm{Cu}_{0.4} \mathrm{Fe}_{12} \mathrm{O}_{22}$ with nano-sized starting powders calcined at $900{ }^{\circ} \mathrm{C}$ 

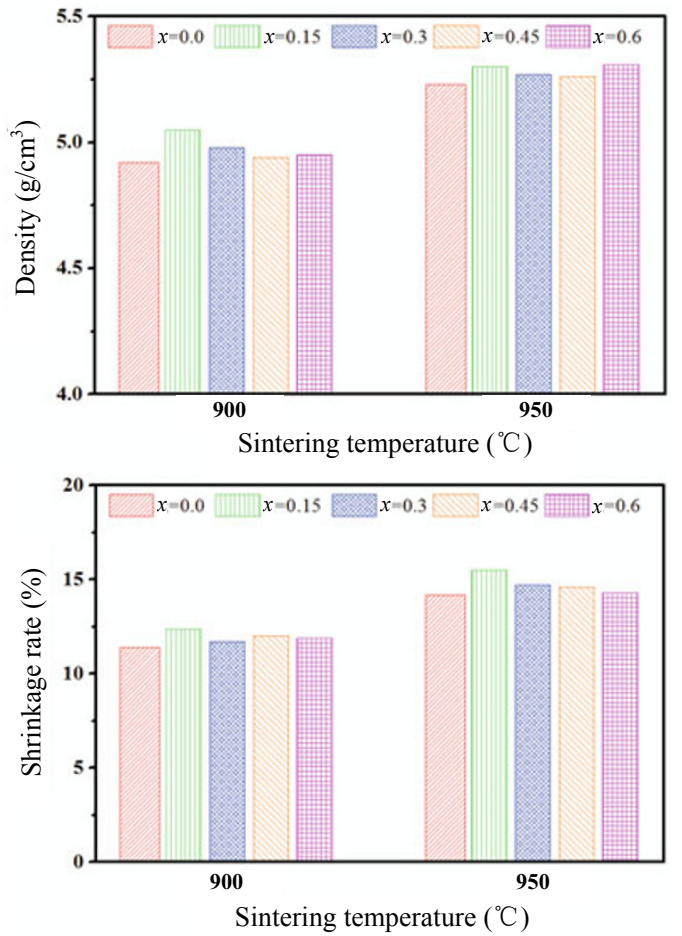

Fig. 2 Density and shrinkage rate of sol-gel method prepared $\mathrm{Ba}_{2} \mathrm{Zn}_{1.2-2 x} \mathrm{Co}_{2 x} \mathrm{Cu}_{0.8} \mathrm{Fe}_{12} \mathrm{O}_{22}$

using micron-sized powder sintered at high temperature.

Figure 3 compares the permeability of the samples made by different starting powders. To exclude the effect of microstructure on permeability, the samples with similar density are selected in the comparison, where the samples using nano-sized powders are sintered at $900{ }^{\circ} \mathrm{C}$, and those using micron-sized powders at $1000{ }^{\circ} \mathrm{C}$. The samples using nano-sized starting powders have higher permeability and the enhancement of permeability is notable for the samples with high $\mathrm{Zn}$ amount.

\section{Substitution of low-melting elements in the lattice}

The substitution of low-melting elements in ferrite can lower the sintering temperature effectively, because some liquid phase occurs at high temperature to promote the mass transfer in liquid phase during the sintering process. This method is convenient in the preparation process and facilitates to achieve homogeneous ion distribution and microstructure. However, its effect is often confined by the substitution limit associated with the difference of ion radii.

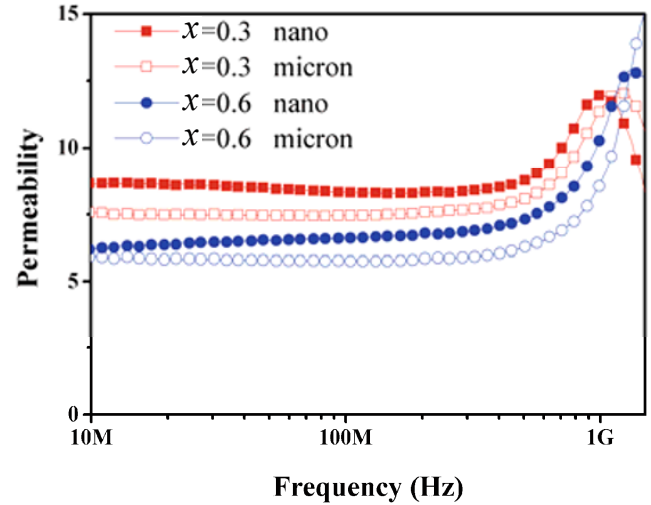

Fig. 3 Frequency dependence of the permeability of $\mathrm{Ba}_{2} \mathrm{Zn}_{1.2-2 x} \mathrm{Co}_{2 x} \mathrm{Cu}_{0.8} \mathrm{Fe}_{12} \mathrm{O}_{22} \quad(x=0.3$ and 0.6$)$ prepared using different starting powders

\subsection{Cu substitution}

$\mathrm{Cu}^{2+}$ ion is the most common ion in ferrites and can lower the sintering temperature, because of the formation of liquid phase of $\mathrm{Cu}$-containing compounds at high temperature. In addition, $\mathrm{Cu}$ ion has similar radius as $\mathrm{Fe}$ ion, which work for its substitution in ferrites. The $\mathrm{Cu}$ substation in spinel ferrites [19-23] and hexagonal ferrites [2-4,24,25], has been well studied, and it was proved efficient in Y-type hexagonal ferrites [6-8, 26-31].

Because the $\mathrm{Cu}$-containing compounds with low melting temperature are formed to promote the mass transfer in liquid phase, the phase formation temperature is lowered effectively with $\mathrm{Cu}$ substitution. As shown in Fig. 4, $\mathrm{Ba}_{2} \mathrm{Co}_{2} \mathrm{Fe}_{12} \mathrm{O}_{22}$ without $\mathrm{Cu}$ substitution forms pure phase of Y-type hexagonal ferrite until $1050{ }^{\circ} \mathrm{C}$, while the temperature is lowered

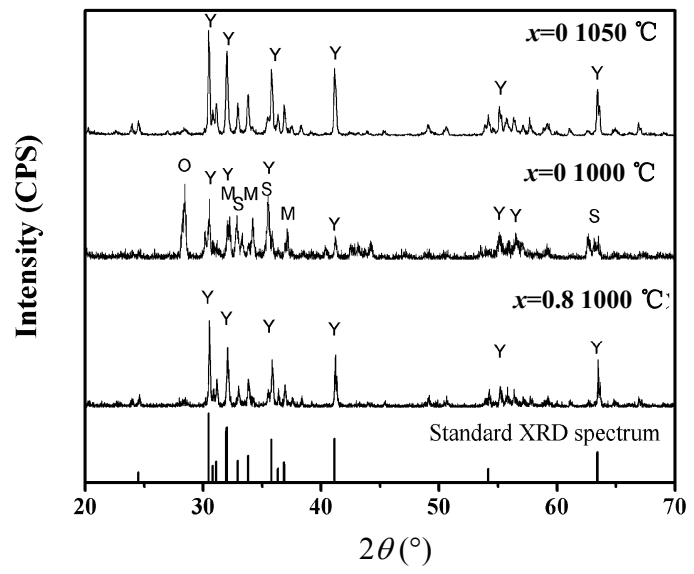

Fig. 4 XRD pattern of $\mathrm{Ba}_{2} \mathrm{Co}_{2-x} \mathrm{Cu}_{x} \mathrm{Fe}_{12} \mathrm{O}_{22}$ hexagonal ferrite calcined at different temperatures 
to $1000{ }^{\circ} \mathrm{C}$ in $\mathrm{Ba}_{2} \mathrm{Co}_{1.2} \mathrm{Cu}_{0.8} \mathrm{Fe}_{12} \mathrm{O}_{22}$ due to $\mathrm{Cu}$ substitution.

The dependences of shrinkage rate and density on the sintered samples, shown in Fig. 5, indicate the obvious effect of $\mathrm{Cu}$ substitution on lowering the sintering temperature. The higher the sintering temperature, the lower the sintering temperature is. The density of the sample with $\mathrm{Cu}$ amount of $x=0.8$ reaches $95 \%$ of theoretical density after sintered at $1000{ }^{\circ} \mathrm{C}$, which is $150{ }^{\circ} \mathrm{C}$ lower than that for the sample without $\mathrm{Cu}$ substitution. But $\mathrm{Cu}$ substitution is hard to lower the sintering temperature of Y-type hexagonal ferrite below $1000{ }^{\circ} \mathrm{C}$. The sintering temperature of pure $\mathrm{Cu}_{2} \mathrm{Y}$ hexagonal ferrite $\left(\mathrm{Ba}_{2} \mathrm{Co}_{2-\mathrm{x}} \mathrm{Cu}_{\mathrm{x}} \mathrm{Fe}_{12} \mathrm{O}_{22}\right)$ is just $1000{ }^{\circ} \mathrm{C}$.

The species and distribution of transition metal ions in ferrite determine the magnetic properties. In Y-type hexagonal ferrite, $\mathrm{Co}^{2+}$ and $\mathrm{Zn}^{2+}$ ions are the most efficient substitutions to modify magnetic properties. $\mathrm{Co}^{2+}$ ions help raising the planar anisotropy, which works for the rise of cut-off frequency and reduces the permeability. On the contrary, $\mathrm{Zn}^{2+}$ ions help increasing the saturation magnetization and reducing
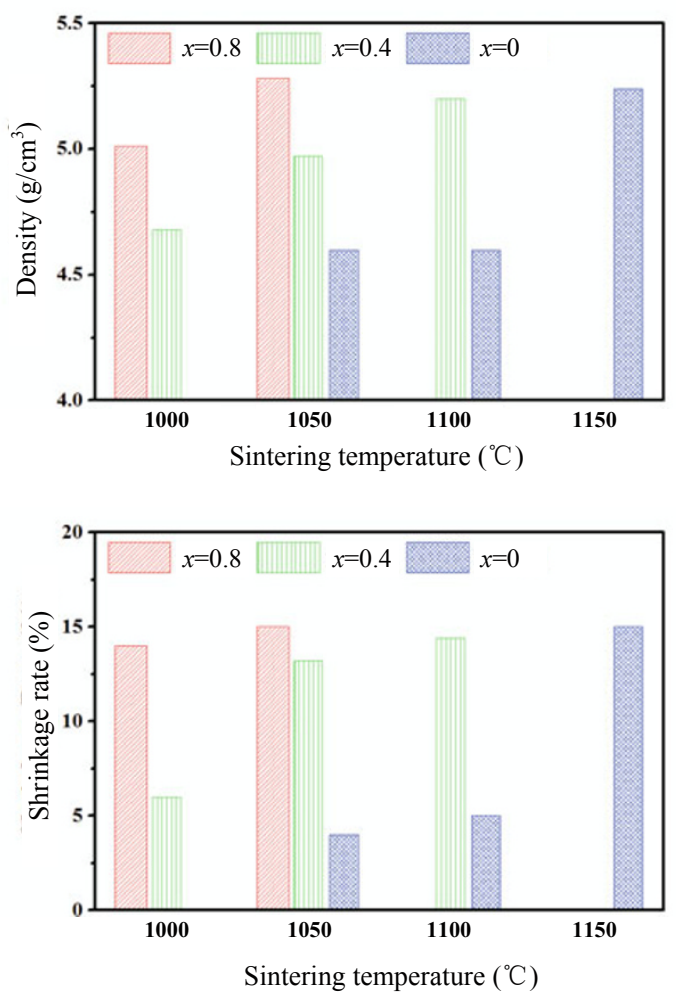

Fig. 5 (a) Densities and (b) shrinkage rate of $\mathrm{Ba}_{2} \mathrm{Co}_{0.6} \mathrm{Zn}_{1.2-x} \mathrm{Cu}_{x} \mathrm{Fe}_{12} \mathrm{O}_{22}$ hexagonal ferrite sintered at different temperatures the magnetic anisotropy, so inverse effect is expected. Figure 6 shows the frequency dependence of the permeability of $\mathrm{Ba}_{2} \mathrm{Zn}_{1.2-x} \mathrm{Co}_{x} \mathrm{Cu}_{0.8} \mathrm{Fe}_{12} \mathrm{O}_{22}$ hexagonal ferrites sintered at $1000{ }^{\circ} \mathrm{C}$. The permeability increases monotonically with the rise of $\mathrm{Zn}$ amount and the drop of Co amount.

$\mathrm{Cu}$ substitution in the Y-type hexagonal ferrite can also affect the magnetic properties. To avoid the effect of microstructure, the samples with similar density have been used in the comparison. Figure $7 \mathrm{a}$ indicates the effect of $\mathrm{Cu}$ substitution on $\mathrm{Zn}$, which is shown that the permeability decreases with the rise of $\mathrm{Cu}$ substitution but the cut-off frequency raises, due to the reduction of saturation magnetization and the increase of anisotropy. Figure $7 \mathrm{~b}$ shows the effect of $\mathrm{Cu}$ substitution on Co. The permeability increases slightly with the rise of $\mathrm{Cu}$ amount, because the reduction of Co amount declines the anisotropy. It is also found that the sample with high $\mathrm{Zn}$ amount is more sensitive to $\mathrm{Cu}$ substitution, because high $\mathrm{Zn}$ amount endows the samples low magnetic anisotropy.

\subsection{Bi substitution}

$\mathrm{Bi}_{2} \mathrm{O}_{3}$ is one of the most common sintering additives in ferrites and can efficiently lower the sintering temperature. $\mathrm{Bi}^{3+}$ can be also used as a substitution in the lattice of hexagonal ferrite. Pal and Winotaia reported the results with $\mathrm{Bi}$ substitution on $\mathrm{Fe}$ in M-type hexaferrite [32-35]. However, the valance variation of $\mathrm{Bi}$ and $\mathrm{Fe}$ ions destroys the dielectric character obviously, so such substitution is not suitable for the soft magnetic ferrite. In addition, $\mathrm{Bi}$ can also substitute for $\mathrm{Ba}$ due to their similar radius, which has been proved feasible in hexagonal ferrites, such as Y-type and Z-type hexagonal ferrites [36-38], to lower

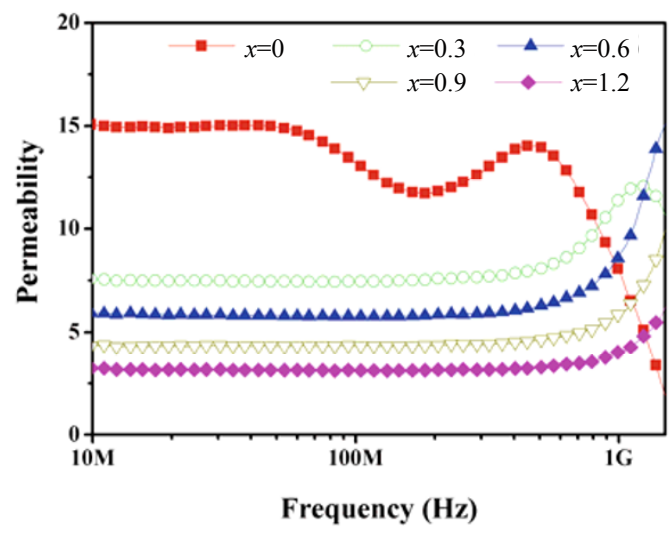

Fig. 6 Frequency dependence of the permeability of $\mathrm{Ba}_{2} \mathrm{Zn}_{1.2-x} \mathrm{Co}_{x} \mathrm{Cu}_{0.8} \mathrm{Fe}_{12} \mathrm{O}_{22}$ sintered at $1000{ }^{\circ} \mathrm{C}$ 


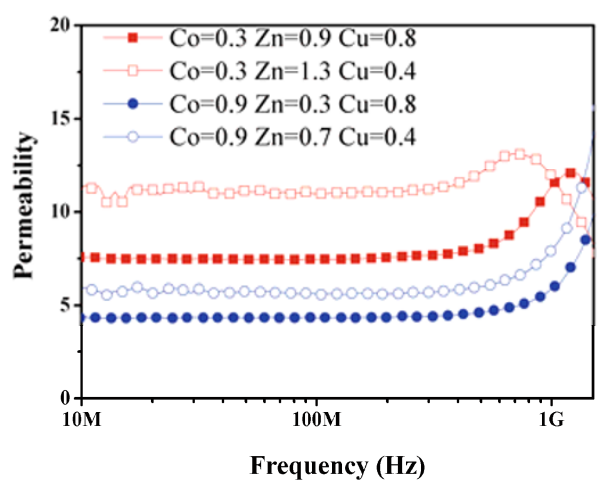

(a)

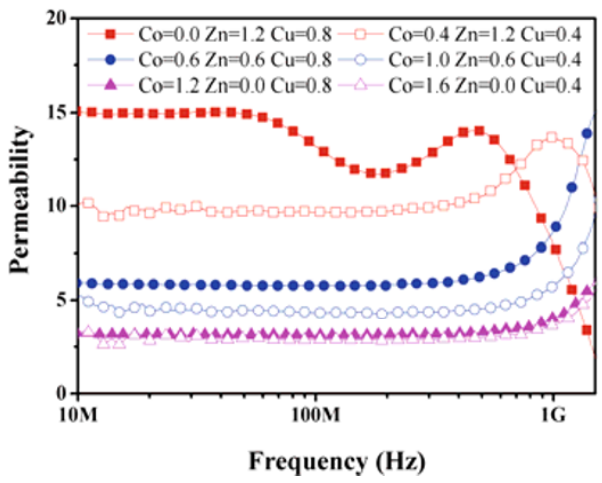

(b)

Fig. 7 Frequency dependence of the permeability of $\mathrm{Ba}_{2} \mathrm{Zn}_{2-x-y} \mathrm{Co}_{y} \mathrm{Cu}_{x} \mathrm{Fe}_{12} \mathrm{O}_{22}$. (a) Co amount is fixed; (b) $\mathrm{Zn}$ amount is fixed. The $x=0.8$ samples were sintered at $1000{ }^{\circ} \mathrm{C}$, and the $x=0.4$ samples at $1050{ }^{\circ} \mathrm{C}$.

the sintering temperature. Because the valences of $\mathrm{Bi}^{3+}$ and $\mathrm{Ba}^{2+}$ are different, identical amount of divalent ion with, such as $\mathrm{Co}^{2+}$ or $\mathrm{Zn}^{2+}$, should substitute $\mathrm{Fe}^{3+}$ ion at the same time for the electrovalence balance.

Similar to $\mathrm{Cu}$ substitution, Bi substitution can also lower the phase formation temperature of Y-type hexagonal ferrite. As shown in Fig. 8, without the aid of Bi substitution, the pure phase of Y-type hexagonal ferrite does not be obtained after calcined at $900{ }^{\circ} \mathrm{C}$. However, minor $\mathrm{Bi}$ substitution can lower the phase formation temperature to $900{ }^{\circ} \mathrm{C}$ and shorten the calcination duration. And higher $\mathrm{Bi}$ amount benefits the phase formation more. As the $\mathrm{Bi}$ amount raise to $x=0.15$, the pure Y-type hexagonal ferrite is obtained after calcined at $900{ }^{\circ} \mathrm{C}$ for $0.5 \mathrm{~h}$. However, excess Bi substitution may destroy the phase formation of Y-type hexagonal ferrite due to the difference of ion radius between $\mathrm{Bi}$ and $\mathrm{Ba}$ ions, and pure phase cannot be obtained as the amount of $\mathrm{Bi}$ is beyond $x=0.3$.

Figure 9 shows the densities and shrinkage rates of Bi substituted Y-type hexagonal ferrites. It is clear that Bi substitution can lower the sintering temperature

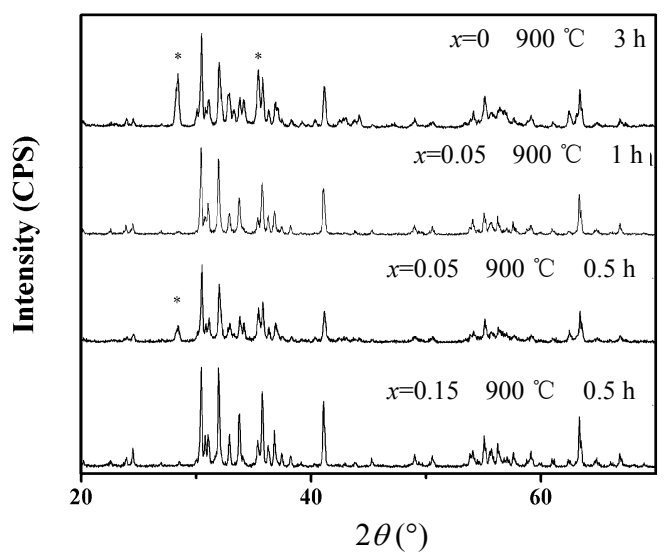

Fig. 8 XRD patterns of $\mathrm{Ba}_{2-x} \mathrm{Bi}_{x} \mathrm{Zn}_{0.8} \mathrm{Co}_{0.8+x} \mathrm{Cu}_{0.4} \mathrm{Fe}_{12-x} \mathrm{O}_{22}$ calcined at $900{ }^{\circ} \mathrm{C}$

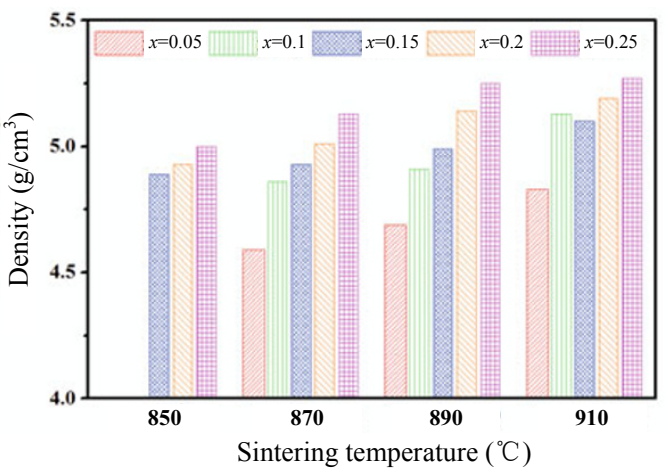

(a)

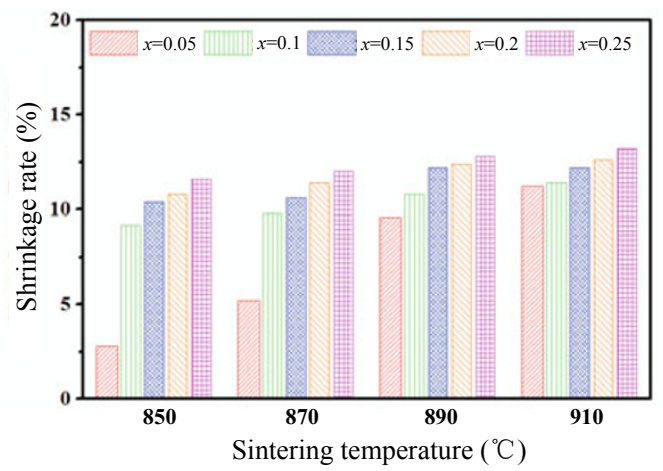

(b)

Fig. 9 (a) Densities and (b) shrinkage rates of $\mathrm{Ba}_{2-x} \mathrm{Bi}_{x} \mathrm{Zn}_{0.8} \mathrm{Co}_{0.8+x} \mathrm{Cu}_{0.4} \mathrm{Fe}_{12-x} \mathrm{O}_{22}$ hexagonal ferrite sintered at different temperatures

efficiently. The higher the $\mathrm{Bi}$ amount, the lower the sintering temperature is. The samples with minor $\mathrm{Bi}$ amount $(x>0.05)$ can be sintered well under $900{ }^{\circ} \mathrm{C}$, which meets the need to cofire with $\mathrm{Ag}$ electrode in LTCC technology. The sintering temperature is lowered about $150{ }^{\circ} \mathrm{C}$ compared with that of the sample without Bi substitution.

Bi substitution also affects the magnetic properties 
of Y-type hexagonal ferrites. Figure 10 shows the permeability of Y-type hexagonal ferrites with Bi-Co substitution and $\mathrm{Bi}-\mathrm{Zn}$ substitution, where the samples with similar densification are selected in the comparison to exclude the influence of microstructure. The permeability declines monotonically with the rise of Bi-Co substitution, while it increases first, reaches a maximum at $x=0.15$, and then decreases for the $\mathrm{Bi}-\mathrm{Zn}$ substitued samples. As the permeability may decrease with Co subtitution and increase with $\mathrm{Zn}$ substitution monotonically, the effect of $\mathrm{Bi}$ substitution on permeabiltiy is concluded to be negative. There may be two reasons, the internal stress due to the different ion radius and the change of magnetic ion distribution in the lattice. The relationship between permeability and internal stress can be expressed by

$$
\mu \propto \frac{M_{s}^{2}}{K_{1}+\lambda_{s} \sigma}
$$

where $M_{s}$ stands for saturation magnetization, $K_{1}$ for magneto-crystalline anisotropy, $\lambda_{s}$ for magnetostriction factor and $\sigma$ for internal stress. The substitution of $\mathrm{Bi}$ on $\mathrm{Ba}$ may induce internal stress in lattice due to ion radii difference, which makes permeability decline. On

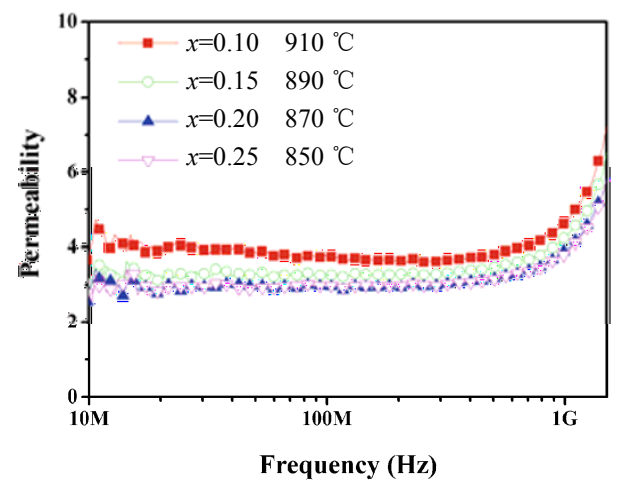

(a)

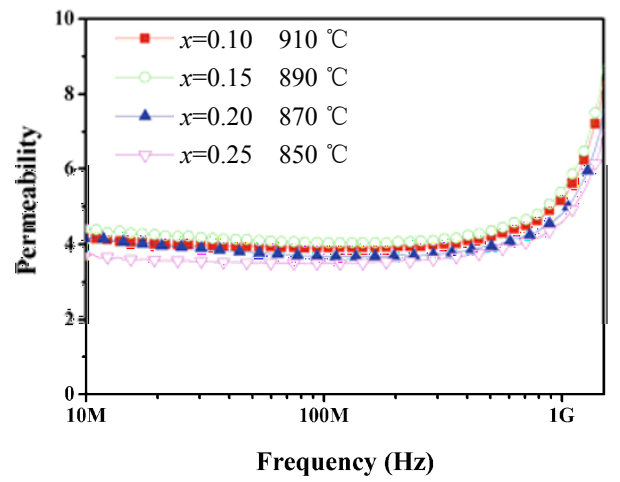

(b)

Fig. 10 Frequency dependence of the permeability of (a) $\mathrm{Ba}_{2-x} \mathrm{Bi}_{x} \mathrm{Zn}_{0.8} \mathrm{Co}_{0.8+x} \mathrm{Cu}_{0.4} \mathrm{Fe}_{12-x} \mathrm{O}_{22}$ and (b) $\mathrm{Ba}_{2-x} \mathrm{Bi}_{x} \mathrm{Zn}_{0.8+x} \mathrm{Co}_{0.8} \mathrm{Cu}_{0.4} \mathrm{Fe}_{12-x} \mathrm{O}_{22}$ the other hand, the substitution in Ba site can change the ion distribution of transition metal ions in the interstitial site. For exsample, Sr substitution on $\mathrm{Ba}$ will make more $\mathrm{Fe}^{3+}$ into A sites antiparallel to the total magnetic moment, which make the permeability reduce.

\section{Sintering additives with low melting point}

Adding the low-melting sintering additives is the most common method to promote sintering process and lower the sintering temperature. After pure ferrite phase is formed after calcination, the additives are mixed with the ferrite powders during the second ball milling [39-43]. Different additives may play various roles in the sintering process. Some additive melts at high temperature, and promotes the mass transfer liquid phase. Some additive speeds up the solid state reaction by producing highly active interphase. Some additive accelerates the densification by large shrinkage when coating the ferrite particles. In general, the existence of liquid phase during sintering process is important for the sintering densification. Among various sintering additives, oxides and glasses with low melting point are most common. Here, $\mathrm{Bi}_{2} \mathrm{O}_{3}$ and $\mathrm{B}_{2} \mathrm{O}_{3}-\mathrm{PbO}$ glass are selected as examples.

Figure 11 compared the density and shrinkage rate of $\mathrm{Ba}_{2} \mathrm{Zn}_{1.2-x} \mathrm{Co}_{x} \mathrm{Cu}_{0.8} \mathrm{Fe}_{12} \mathrm{O}_{22}$ with different sintering additives sintered at $870{ }^{\circ} \mathrm{C}$ for $6 \mathrm{~h}$. The samples with same additives have similar density and shrinkage rate after sintered at same condition. As the sintering temperature is higher than $850{ }^{\circ} \mathrm{C}$, the samples with $\mathrm{Bi}_{2} \mathrm{O}_{3}$ doping have high densities beyond $5.0 \mathrm{~g} / \mathrm{cm}^{3}$ (about $93 \%$ of theory density), which proves the excellent low-firing effect of $\mathrm{Bi}_{2} \mathrm{O}_{3}$. Although the $\mathrm{B}_{2} \mathrm{O}_{3}-\mathrm{PbO}$ glass doped samples exhibits larger sintering shrinkage rate, but the density is not as high as expected. The shrinkage rate of the sample with $5 \mathrm{wt} \%$ glass doping sintered at $870{ }^{\circ} \mathrm{C}$ for $6 \mathrm{~h}$ exceeds $13 \%$, much larger than those of the $\mathrm{Bi}_{2} \mathrm{O}_{3}$ doped samples, but their densities are just under $4.85 \mathrm{~g} / \mathrm{cm}^{3}$ (about $88 \%$ of theory density).

The different sintering behavior originates from the different effects of sintering additives in sintering process. $\mathrm{B}_{2} \mathrm{O}_{3}-\mathrm{PbO}$ glass melts at lower temperature and coats the ferrite particles, which greatly promotes the sintering shrinkage but the densification of microstructure is far from sufficient. The effect of $\mathrm{Bi}_{2} \mathrm{O}_{3}$ is only to promote the liquid-phase mass transfer 


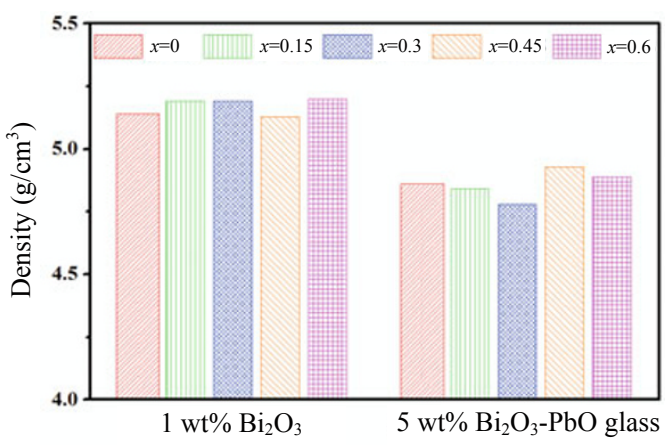

(a)

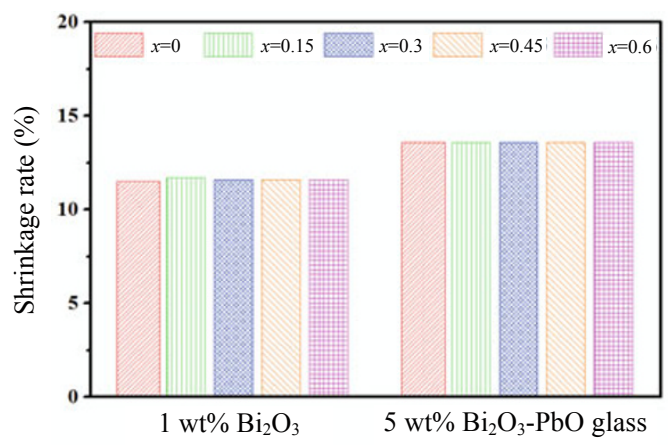

(b)

Fig. 11 (a) Densities and (b) shrinkage rate of $\mathrm{Ba}_{2} \mathrm{Zn}_{1.2-2 x} \mathrm{Co}_{2 x} \mathrm{Cu}_{0.8} \mathrm{Fe}_{12} \mathrm{O}_{22}$ with different sintering additives sintered at $870{ }^{\circ} \mathrm{C}$ for $6 \mathrm{~h}$

at high temperature, and the amount is not enough to coat the ferrite particles.

The different effects of sintering additives also affect the magnetic properties. Figure 12 compares the permeability of the samples with different sintering additives. The permeability of the low-fired samples has similar frequency dispersion characters as those of the samples without additives and sintered at high temperature, but the value of permeability is lowered

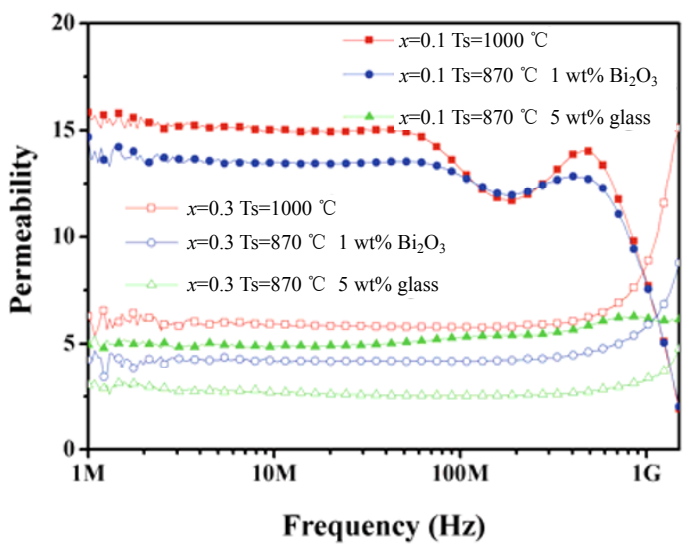

Fig. 12 Frequency dependence of the permeability of $\mathrm{Ba}_{2} \mathrm{Zn}_{1.2-2 x} \mathrm{Co}_{2 x} \mathrm{Cu}_{0.8} \mathrm{Fe}_{12} \mathrm{O}_{22}$ with different sintering additives slightly. It is clear that the reduction of permeability is slight in the $\mathrm{Bi}_{2} \mathrm{O}_{3}$ doped samples, but severe in the glass doped samples. For example, the permeability of $\mathrm{Ba}_{2} \mathrm{Zn}_{1.2} \mathrm{Cu}_{0.8} \mathrm{Fe}_{12} \mathrm{O}_{22}$ sintered at $1000{ }^{\circ} \mathrm{C}$ is 15 , while that of $1 \mathrm{wt} \% \mathrm{Bi}_{2} \mathrm{O}_{3}$ doped samples sintered at $890{ }^{\circ} \mathrm{C}$ is 13 , and that of $5 \mathrm{wt} \%$ glass doped samples is only 5 . That is beause that the mass of nonmagnetic glass coats the ferrit grain and blocks the magnetic current. On the other hand, the glass doped samples may have better dielectric and resistivity property, low due to the low permittivity and high resistivity of large amount of glass in the grain boundary.

\section{Lattice defect by nonstoichiometry}

Mass transfer in solid phase is also an important process for sintering, which can be accelerated by ion vacancy. The ion vacancy includes cation vacancy and anion vacancy. Because anion vacancy can promote the valence variation of transition metal, which works against the electric properties, the cation vacancy is always used. The cation vacancy can be formed by the substitution of high-valence ions ( $\mathrm{W}^{6+}$ etc.) and nonstoichiometric composition with cantion deficiency. Considering that the substitution of nonmagnetic ions may influence the magnetic properties, the Y-type hexagonal ferrites with $\mathrm{Fe}^{3+}$ cation deficiency $\left(\mathrm{Ba}_{2} \mathrm{Zn}_{0.6} \mathrm{Co}_{0.6} \mathrm{Cu}_{0.8} \mathrm{Fe}_{12-x} \mathrm{O}_{22-1.5 x}\right)$ were studied in some reports $[44,45]$.

$\mathrm{Fe}^{3+}$ ions occupy the interstitial sites of the lattice, so small amount of cation deficiency does not damage the phase formation of Y-type hexagonal ferrite. Fig. 13 shows the XRD patterns of the samples with different cation deficiency. As $x \leqslant 1.0$, the phase

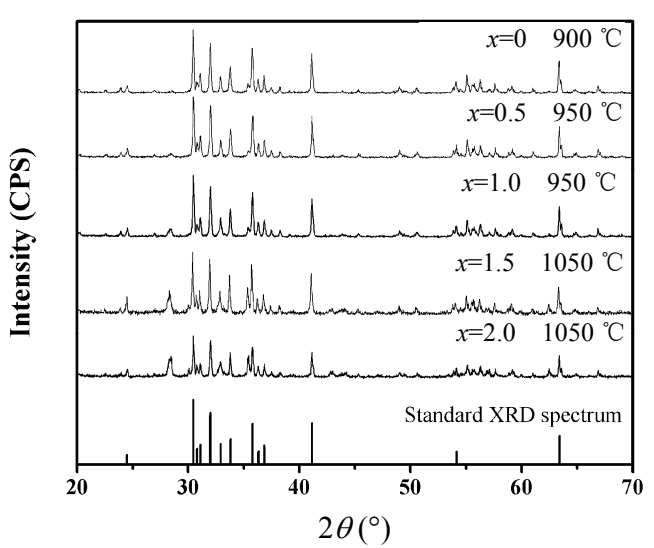

Fig. 13 XRD patterns of $\mathrm{Ba}_{2} \mathrm{Zn}_{0.6} \mathrm{Co}_{0.6} \mathrm{Cu}_{0.8} \mathrm{Fe}_{12-x} \mathrm{O}_{22-1.5 x}$ calcined at $950^{\circ} \mathrm{C}$ and $1050^{\circ} \mathrm{C}$ 
formation is not affected and pure Y-type hexagonal ferrite can be formed at $1000{ }^{\circ} \mathrm{C}$ However, when the cation deficient $(x \geqslant 1.5)$ is more, the phase formation will be destroy, and many other phases, such as $\mathrm{BaFe}_{2} \mathrm{O}_{4}$, always accompany with Y-type hexagonal ferrite although calcining temperature further rises to $1050{ }^{\circ} \mathrm{C}$.

Figure 14 shows the density and shrinkage rate of the samples sintered at different temperatures. It is clear that the samples with cation deficiency have much lower densification temperature because the mass transfer in solid phase is accelerated by ion vacancy during the sintering process. Their density and shrinkage rate are both much lower than those of the sample without cation deficiency. The samples with $\mathrm{Fe}^{3+}$ ion deficiency can be sintered well at $950{ }^{\circ} \mathrm{C}$, about $50{ }^{\circ} \mathrm{C}$ lower than the sample with stoichiometric proportion. It indicates that the ion vacancy can benefit the sintering process efficiently, but the effect on the mass transfer in solid phase is not quite as well as that in liquid phase, because the mass transfer in liquid phase is more crucial for the sintering process.

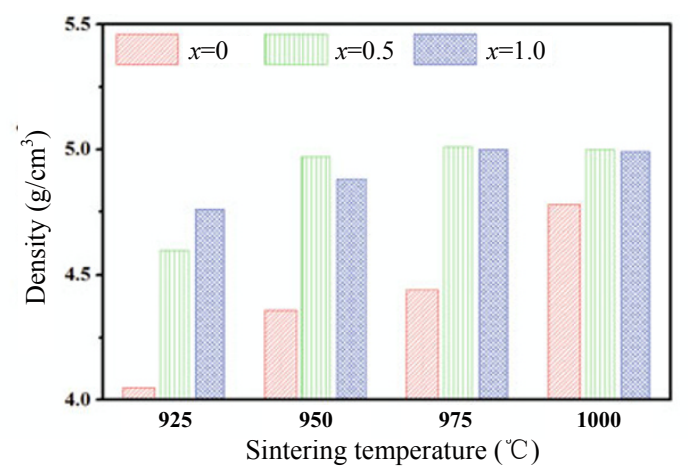

(a)

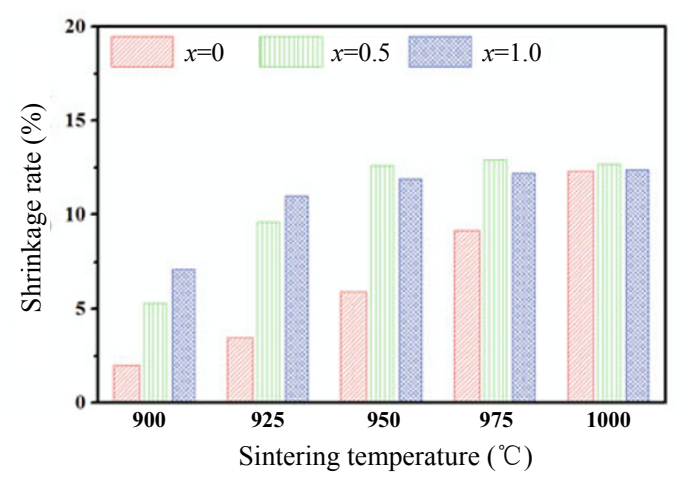

(b)

Fig. 14 (a) Densities and (b) shrinkage rate of $\mathrm{Ba}_{2} \mathrm{Zn}_{0.6} \mathrm{Co}_{0.6} \mathrm{Cu}_{0.8} \mathrm{Fe}_{12-x} \mathrm{O}_{22-1.5 x}(0 \leqslant x \leqslant 1.0)$ sintered at different temperatures
Figure 15 shows the frequency dispersion of the permeability of the samples sintered at $950{ }^{\circ} \mathrm{C}$. All the samples exhibits stable permeability within $10 \mathrm{MHz}$ to $1 \mathrm{GHz}$, and there is no obvious frequency dispersion. In addition, the magnetic low loss is low the in whole frequency range. All these will great benefit the application in hyper-frequency. Figure 16 compares the permeability (@300 MHz) of the samples sintered at different temperatures. The permeability of the $x=0$ samples with stoichiometric proportion increases linearly with the rise of sintering temperature due to the sintering densification. After sinter at $1000{ }^{\circ} \mathrm{C}$, the sample has a fully dense microstructure and the permeability reaches $\sim 5.5$. The permeability of the $x=0.5$ sample reaches a high value of $\sim 5.8$ at a low temperature of $950{ }^{\circ} \mathrm{C}$ because of its low densification temperature. For the $x=1.0$ samples, the permeability is always low, because the cation deficiency induces lattice stress to block the motion of domain wall and the spin rotation, and promotes the volatilization of $\mathrm{Zn}$.

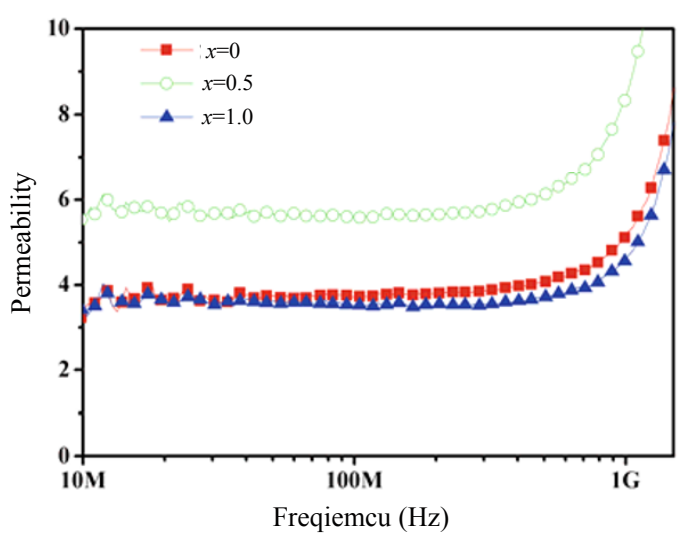

Fig. 15 Frequency dispersion of the permeability of $\mathrm{Ba}_{2} \mathrm{Zn}_{0.6} \mathrm{Co}_{0.6} \mathrm{Cu}_{0.8} \mathrm{Fe}_{12-x} \mathrm{O}_{22-1.5 x}$ sintered at $950{ }^{\circ} \mathrm{C}$

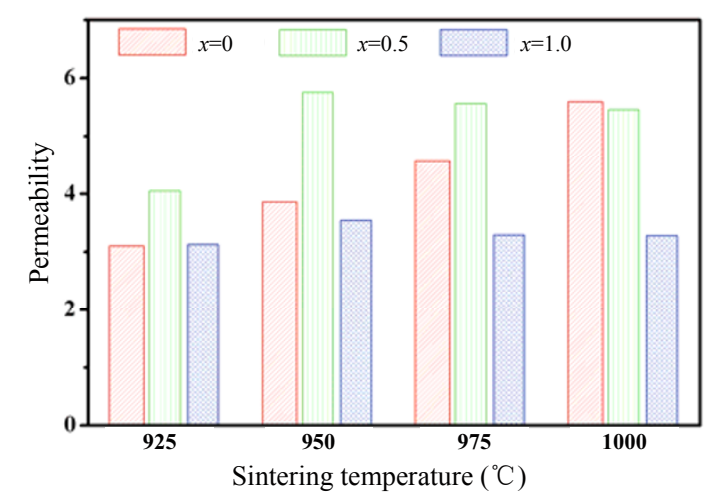

Fig.16 Variation of permeability (@300MHz) of $\mathrm{Ba}_{2} \mathrm{Zn}_{0.6} \mathrm{Co}_{0.6} \mathrm{Cu}_{0.8} \mathrm{Fe}_{12-x} \mathrm{O}_{22-1.5 x}$ sintered at different temperatures 


\section{Conclusions}

Y-type hexagonal ferrite is a crucial magnetic material owing to its excellent magnetic properties in hyper frequency. It will play more and more important role in electronic industry with the trend towards high frequency. For its application in multilayer inductive devices, the low-firing technology is a key in LTCC. Lowering the temperature can be realized by either increasing the driving force of sintering or accelerating the mass transfer during the sintering process. Although there are several methods to lower the sintering temperature, the obtained low-fired samples have different electromagnetic properties. It is important to choose proper low-firing methods or their combination in practical application.

\section{Acknowledgement}

This work was supported by grants from the National Natural Science Foundation of China (No. 51172020), and the Fundamental Research Funds for the Central Universities (No. FRF-TP-09-028A).

\section{Reference}

[1] Smit J, Wijn HBJ. Ferrites. London, UK: Cleaver-Hume Press, 1959.

[2] Zhang HG, Zhou J, Wang YL, et al. Microstructure and physical characteristics of novel Z-type hexaferrite with $\mathrm{Cu}$ modification. $J$ Electroceram 2002, 9: 73-79.

[3] Zhang HG, Zhou J, Wang YL, et al. Investigation on physical characteristics of novel Z-type $\mathrm{Ba}_{3} \mathrm{Co}_{2(0.8-x)} \mathrm{Cu}_{0.40} \mathrm{Zn}_{2 x} \mathrm{Fe}_{24} \mathrm{O}_{41}$ hexaferrite. Mater Lett 2002, 56: 397-403.

[4] Zhang HG, Zhou J, Wang YL, et al. The effect of Zn ion substitution on electromagnetic properties of low-temperature fired Z-type hexaferrite. Ceram Inter 2002, 28: 917-923.

[5] Kračunovska S, Töpfer J. Preparation, thermal stability and permeability behavior of substituted Z-type hexagonal ferrites for multilayer inductors. $J$ Electroceram 2009, 22: 227-232.

[6] Bai Y, Zhou J, Gui ZL, et al. An investigation of the magnetic properties of $\mathrm{Co} 2 \mathrm{Y}$ hexaferrite. Mater Lett 2002, 57: 807-811.

[7] Bai Y, Zhou J, Gui ZL, et al. Magnetic properties of $\mathrm{Cu}, \mathrm{Zn}$ modified Co2Y hexaferrites. J Magn Magn Materials 2002, 246: 140-144.

[8] Bai Y, Zhou J, Gui ZL, et al. Complex Y-type hexagonal ferrites: an ideal material for high frequency chip magnetic components. J Magn MagnMater 2003, 264: 44-49.

[9] Lisjakw D, Drofenik M. Influence of $\mathrm{Ag}$ on the composition and electromagnetic properties of low-temperature cofired hexaferrites. J Am Ceram Soc 2007, 90: 3121-3126.

[10] Lisjakw D, Drofenik M. Thermal stability of $(\mathrm{Co}, \mathrm{Cu}) \mathrm{Z}-\mathrm{Hexaferrite}$ and its compatibility with $\mathrm{Ag}$ at $900^{\circ} \mathrm{C} . \mathrm{J} \mathrm{Am} \mathrm{Ceram} \mathrm{Soc} \mathrm{2007,} \mathrm{90:} \mathrm{3517-3521.}$

[11] Kingery WD, Bowen HK, Uhlmann DR. Introduction to Ceramics (2nd ed.). New York, US: John Wiley \& Sons, Academic Press, 1976.

[12] Daigle A, DuPre E, Geiler A, et al. Preparation and characterization of pure-phase $\mathrm{Co}_{2} \mathrm{Y}$ ferrite powders via a scalable aqueous coprecipitation method. $J \mathrm{Am}$ Ceram Soc 2010, 93: 2994-2997.

[13] Zhang CX, Shi JS, Yang XJ, et al. Effects of calcination temperature and solution $\mathrm{pH}$ value on the structural and magnetic properties of $\mathrm{Ba}_{2} \mathrm{Co}_{2} \mathrm{Fe}_{12} \mathrm{O}_{22}$ ferrite via EDTA-complexing process. Mater Chem Phys 2010, 123: 551-556.

[14] Nagae M, Atsumi T, Yoshio T. Preparation of Y-type barium hexaferrite by the glass-ceramic method. $J$ Am Ceram Soc 2006, 89: 1122-1124.

[15] Bai Y, Zhou J, Gui ZL, et al. Phase formation process, microstructure and magnetic properties of Y-type hexagonal ferrite prepared by citrate sol-gel auto- combustion method. Mater Chem Phys 2006, 98: 66-70.

[16] Bai Y, Zhou J, Gui ZL, et al. Preparation and magnetic properties of Y-type ferroxplana by sol-gel method. Key Eng Mater 2005, 280-283: 477-480.

[17] Cai JH, Dai LQ, Zhou XB. Thermodynamic analysis on preparation of zinc doped $\mathrm{Co}_{2}-\mathrm{Y}$ planar hexagonal ferrite powder by chemical co-precipitation method. Chinese J Inorg Chem 2008, 24: 1943-1948.

[18] Cai JH, Dai JQ, Chen WG, et al. Thermodynamic analysis on solubility of $\mathrm{Fe}^{3+} / \mathrm{Ba}^{2+} / \mathrm{Co}^{2+} / \mathrm{Zn}^{2+} / \mathrm{Cu}^{2+}$ in $\mathrm{NH}_{4} \mathrm{HCO}_{3}-\mathrm{NH}_{3}$ center dot $\mathrm{H}_{2} \mathrm{O}$ and $\mathrm{NaOH}-\mathrm{Na}_{2} \mathrm{CO}_{3}$ system. Chinese J Inorg Chem 2009, 25: 886-892.

[19] Hsu JY. Low temperature fired NiCuZn ferrite. IEEE T Magen 1994, 30: 4875-4877.

[20] Nam JH, Jung HH, Shin JY, et al. Effect of $\mathrm{Cu}$ substitution on the electrical and magnetic properties of NiZn ferrites. IEEE T Magn 1995, 31: 3985-3987.

[21] Zhang HG, Ma ZW, Zhou J, et al. Preparation and investigation of $\left(\mathrm{Ni}_{0.15} \mathrm{Cu}_{0.25} \mathrm{Zn}_{0.60}\right) \mathrm{Fe}_{1.96} \mathrm{O}_{4}$ ferrite with very high initial permeability from self-propagated powders. J Magn Magn Mater 2000, 213: 304-308.

[22] Low KO, Sale FR. The development and analysis of 
property-composition diagrams on gel-derived stoichiometric NiCuZn ferrite. J Magn Magn Mater 2003, 256: 221-226.

[23] Mürbe J, Töpfer J. High permeability Ni-Cu-Zn ferrites through additive-free low-temperature sintering of nanocrystalline powders. $J$ Euro Ceram Soc 2012, 32: 1091-1098.

[24] Wang XH, Ren TL, Li LT, et al. Synthesis of $\mathrm{Cu}$-modified $\mathrm{Co}_{2} \mathrm{Z}$ hexaferrite with planar structure by a citrate precursor method. J Magn Magn Mater 2001, 234: 255-260.

[25] Kračunovska S, Töpfer J. Synthesis, sintering behavior and magnetic properties of $\mathrm{Cu}$-substituted $\mathrm{Co}_{2} \mathrm{Z}$ hexagonal ferrites. J Mater Sci: Mater Electron 2011, 22: 467-473.

[26] Bai Y, Zhou J, Yue ZX, et al. Magnetic properties of composite Y-type hexagonal ferrites in a DC magnetic field. J Appl Phys 2005, 98: 063901.

[27] Bai Y, Zhou J, Gui ZL, et al. The effect of Sr substitution on phase formation and magnetic properties of Y-type hexagonal ferrite. J Am Ceram Soc 2005, 88: 318-323.

[28] Bai Y, Zhou J, Gui ZL, et al. Frequency dispersion of complex permeability of Y-type hexagonal ferrites. Mater Lett 2004, 58: 1602-1606.

[29] Bai Y, Zhou J, Gui ZL, et al. Effect of substitution on magnetization mechanism for Y-type hexagonal ferrite. Mat Sci Eng B 2003, 103: 115-117.

[30] Bai Y, Zhou J, Gui ZL, et al. Preparation and magnetic characterization of $\mathrm{Y}$ - type hexaferrites containing zinc, cobalt and copper. Mat Sci Eng B 2003, 99: 266-269.

[31] Bai Y, Zhou J, Gui ZL, et al. Effect of Mn doping on physical properties of Y- type hexagonal ferrite. $J$ Alloy Comp 2009, 473: 505-508.

[32] Winotai P, Thongmee S, Tang IM. Cation distribution in bismuth-doped M-type barium hexaferrite. Mater Res Bull 2000, 35: 1747-1753.

[33] Pal M, Brahma P, Chakravorty D, et al. Magnetic properties of $\mathrm{Ba}$ hexaferrites doped with bismuth oxide. J Magn Magn Mater 1995, 147: 208-212.
[34] Pal M, Brahma P, Chakravorty D. Mixed valency character of bismuth in ferrite lattices. J Mater Sci Lett 1997, 16: 270-272.

[35] Pal M, Brahma P, Chakraborty D, et al. DC conductivity in barium hexaferrites doped with bismuth oxide. Jpn J Appl Phys 1997, 36: 2163-2166.

[36] Bai Y, Zhou J, Gui ZL, et al. The physic properties of Bi-Zn codoped Y-type hexagonal ferrite. J Alloy Comp 2008, 450: 412-416.

[37] Bai Y, Zhou J, Gui ZL, et al. The effect of Bi substitution on phase formation and low temperature sintering of $\mathrm{Y}$ - type hexagonal ferrite. $J$ Electroceram 2008, 21: 349-352.

[38] Hsiang HI, Mei LT, His CH, et al. Crystalline phases and magnetic properties of $\mathrm{Cu}-\mathrm{Bi}-\mathrm{Zn}$ co-doped $\mathrm{Co}_{2} \mathrm{Z}$ ferrites. J Alloy Comp 2011, 509: 3343-3346.

[39] Pires GFM, Rodrigues HO, Almeida JS, et al. Study of the dielectric and magnetic properties of $\mathrm{Co}_{2} \mathrm{Y}$, Y-type hexaferrite $\left(\mathrm{Ba}_{2} \mathrm{Co}_{2} \mathrm{Fe}_{12} \mathrm{O}_{22}\right)$ added with $\mathrm{PbO}$ and $\mathrm{Bi}_{2} \mathrm{O}_{3}$ in the RF frequency range. $J$ Alloy Comp 2010, 493: 326-334.

[40] Bai Y, Zhou J, Gui ZL, et al. Low-temperature sintered Y-type hexaferrites and their frequency properties. J Func Mater 2002, 33: 487-489.

[41] Bai Y, Zhou J, Gui ZL, et al. Effect of Zn and Co doping on $\mathrm{Co}_{2} \mathrm{Y}$ hexagferrite. Piezoelectrics Acoustooptics 2002, 24: 135-138.

[42] Bai Y, Xu F, Ai F, et al. Study on physical Properties of low temperature sintered $\mathrm{Co}_{2} \mathrm{Y}$. Piezoelectrics Acoustooptics 2008, 30: 335-336.

[43] Kračunovská S, Töpfer J. $\mathrm{Co}_{2} \mathrm{Z}, \mathrm{Co}_{2} \mathrm{Y}$ and CoM-type hexagonal ferrites for multilayer inductors. Key Eng Mater 2010, 434-435: 361-365.

[44] Bai Y, Zhou J, Gui ZL, et al. Electrical properties of non-stoichiometric Y-type hexagonal ferrite. J Magn Magn Mater 2004, 278: 208-213.

[45] Bai Y, Zhou J, Gui ZL, et al. Magnetic properties of non-stoichiometric Y-type hexaferrite. J Magn Magn Mater 2002, 250: 364-369. 